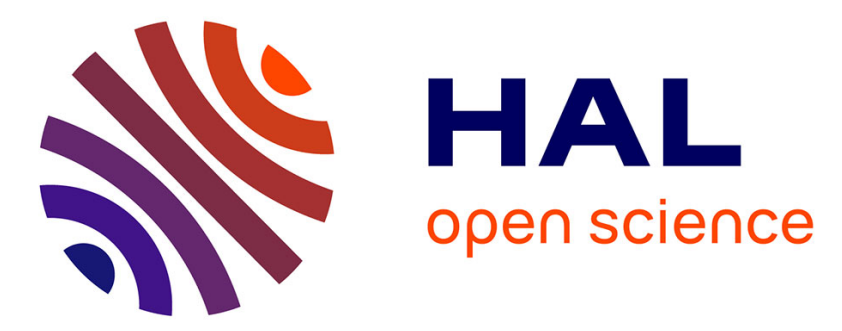

\title{
Nanomechanics and Raman Spectroscopy of in Situ Native Carbohydrate Storage Granules for Enhancing Starch Quality and Lignocellulosic Biomass Production
}

\author{
Rubye Farahi, Aude L. Lereu, Anne Charrier, Udaya C Kalluri, Brian H
} Davison, Ali Passian

\section{To cite this version:}

Rubye Farahi, Aude L. Lereu, Anne Charrier, Udaya C Kalluri, Brian H Davison, et al.. Nanomechanics and Raman Spectroscopy of in Situ Native Carbohydrate Storage Granules for Enhancing Starch Quality and Lignocellulosic Biomass Production. ACS Omega, 2020, 5, pp.2594-2602. 10.1021/acsomega.9b02849 . hal-02469729

\section{HAL Id: hal-02469729 \\ https://hal.science/hal-02469729}

Submitted on 27 Feb 2020

HAL is a multi-disciplinary open access archive for the deposit and dissemination of scientific research documents, whether they are published or not. The documents may come from teaching and research institutions in France or abroad, or from public or private research centers.
L'archive ouverte pluridisciplinaire $\mathbf{H A L}$, est destinée au dépôt et à la diffusion de documents scientifiques de niveau recherche, publiés ou non, émanant des établissements d'enseignement et de recherche français ou étrangers, des laboratoires publics ou privés. 


\section{Nanomechanics and Raman Spectroscopy of in Situ Native Carbohydrate Storage Granules for Enhancing Starch Quality and Lignocellulosic Biomass Production}

Rubye H. Farahi, Aude L. Lereu, Anne M. Charrier, Udaya C. Kalluri, Brian H. Davison, and Ali Passian*

Cite This: ACS Omega 2020, 5, 2594-2602

Read Online

ACCESS | Lلll Metrics \& More | 国 Article Recommendations ｜（s Supporting Information

ABSTRACT: Alternative energy strategies based on plant biomass-derived bioenergy and biofuels rely on understanding and optimization of plant structure, chemistry, and performance. Starch, a constitutive element of all green plants, is important to food, biofuels, and industrial applications. Models of carbohydrate storage granules are highly heterogeneous in representing morphology and structure, though a deeper understanding of the role of structure in functional behavior is emerging. A better understanding of the in situ nanoscale properties of native granules is needed to help improve the starch quality in food crops as well as optimize lignocellulosic biomass production in perennial nonfood crops.

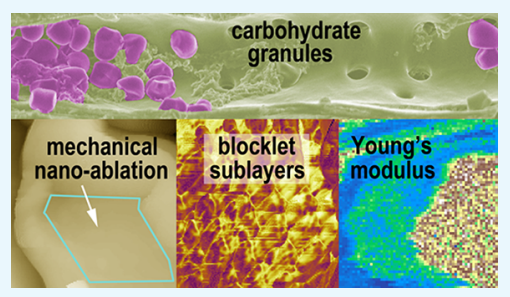
Here, we present a new technique called soft mechanical nano-ablation (sMNA) for accessing the interior of the granules without compromising the inner nanostructure. We then explore the nanomechanics of granules within the ray parenchyma cells of Populus xylem, a desirable woody biofuel feedstock. The employed soft outer layer nanoablation and atomic force microscopy reveal that the inner structure comprises $156 \mathrm{~nm}$ blocklets arranged in a semicrystalline organization. The nanomechanical properties of the inner and outer structures of a single starch granule are measured and found to exhibit large variations, changing by a factor of 3 in Young's modulus and a factor of 2 in viscoplastic index. These findings demonstrate how the introduced approach facilitates studies of structure-function relationships among starch granules and more complex secondary cell wall features as they relate to plant performance.

\section{INTRODUCTION}

Plants, through photosynthesis, produce food in the form of glucose. The excess glucose is converted to starch (amylose and amylopectin) and stored for later use by the plant. These food-storage carbohydrates, occurring as water-insoluble starch granules, are a major food source and industrial material. ${ }^{1}$ Much has been gained in the understanding of the internal structure of the granules in the past 5 decades of starch science $^{2-4}$ with the advent of X-ray diffraction, ${ }^{5,6}$ transmission electron microscopy, ${ }^{7}$ scanning electron microscopy (SEM), ${ }^{8,9}$ and atomic force microscopy (AFM) ${ }^{10,11}$ To characterize the inner structure of the granules, the outer layer of the starch is either digested or exploded using biological or chemical processes such as enzymatic hydrolysis, ${ }^{8}$ lintnerization (mild acid hydrolysis), ${ }^{10}$ dry powder partially affixed with cyanoacrylate, $^{11,12}$ or acid treatment. ${ }^{9}$ These techniques, in conjunction with SEM or AFM, have provided valuable information, but require massive degradation of the granules in order to access their inner structures, thus altering their physical properties. As a less destructive alternative, the probe tip of an AFM has been used as a mechanical "plow" to abrase thin layers of the granule surface; however, individual structures have not been observed at the abrasion sites. ${ }^{13,14}$

In the present work, we introduce an AFM-based soft mechanical nanoablation technique, which we abbreviate as sMNA. We show that sMNA allows the observation of the interior of the granules. Similar to material removal using laser ablation, here, employing sMNA, localized tip indentations are executed to precisely uncouple and displace the outer layer of the granule, leaving the inner architecture intact for further metrology. With the outer layer removed, we carry out nanomechanical measurements and characterization of the exposed inner layer, which, to our knowledge, have not been reported previously. Specifically, we apply the minimally destructive sMNA to in situ native starch granules of Populus and correlate the results with those of starch chemistry and architecture obtained from confocal Raman microscopy and SEM, respectively. Via the minimally destructive sMNA, allowing the gentle removal of the outer material, we identify and obtain evidence of highly ordered blocklets. Acquisition and analysis of nanomechanical forces, presented for both outer and inner regions of the granule, reveal a large difference in the extracted Young's moduli and viscoplasticities.

Macromolecules, that is, very large molecules formed by polymerization of smaller molecules or monomers, can be branched and thus have side chains or branches growing from

Received: September 3, 2019

Accepted: January 13, 2020

Published: February 6, 2020 
the main chain. It is known that starch granules are highly complex macromolecular assemblies of two carbohydrate macromolecules (polysaccharides), amylose and amylopectin. ${ }^{15}$ Although chemically not complex, the architecture of the storage polysaccharide is a complex accumulation of Danhydroglucose units linked by $\alpha-1-4$ and $\alpha-1-6$ glycosidic bonds. Amylopectin, a major constituent comprising 75-90\% of the bulk, is a highly branched macromolecule containing $\alpha$ 1-4 linkages and $\alpha-1-6$ branches (about 5\%). ${ }^{16}$ The clustered organization of packed glucan side chains through the $\alpha-1-6$ glycosidic linkage is responsible for the partial crystalline nature of amylopectin. ${ }^{8}$ Amylose is a smaller macromolecule of $\alpha-1-4$ linked chains with very few branches $(<1 \%)$ that tends to be tightly helical. ${ }^{16}$ The model of the starch structure is still ambiguous; however, it is generally accepted that the branching and layout of amylopectin is not random. ${ }^{1}$ For example, X-ray scattering has shown that clusters of individual amylopectin molecules and their side-chains stack in conservation, the cluster units having a periodicity of 9-10 $\mathrm{nm}$ regardless of plant species. ${ }^{2}$ Upon partial digestion by $\alpha$ amylase enzymes during acid hydrolysis, such starch granules are observed to be composed of growth rings (or shells) of alternating amorphous and semicrystalline layers, with the surviving more resistant semicrystalline layers being 120-400 nm thick. ${ }^{8,17}$ Additionally, spherical "blocklets" between 20 and $500 \mathrm{~nm}$ have been observed in the semicrystalline layers, ${ }^{8}$ which might be explained as a amylopectin super-helix. ${ }^{18}$ The blocklets are composed of alternating amorphous and crystalline "lamellae" of pitch $9-10 \mathrm{~nm}$ relating to the amylopectin side-chain clusters. ${ }^{2}$ Thus, whereas structural features such as granules, growth layers (shells), blocklets, and lamellae (clusters) have been identified, the starch structure continues to be a topic of research because of a lack of a universally accepted model. Nevertheless, it is widely accepted that the molecular structure and amylose/amylopectin ratio are profoundly related to the functional starch properties of morphology (granular size and shape), gelatinization and retrogradation, solubility, digestibility, thermal properties, and paste properties. ${ }^{19}$

To what extent the variations in structure play a role in the plant characteristics is not yet a mature subject, with open questions such as the interdependencies between the formation of starch and biosynthetic enzymes, ${ }^{1}$ the role of starch architecture in plant physiology and starch metabolism, ${ }^{20}$ how the structure of granules influences starch functionality in foods and nutrition, ${ }^{21}$ and the potential use of starch nanoelements for biocomposites. ${ }^{22}$ Moreover, understanding the role of seasonal variation in starch granules in woody perennial plants and correlation to annual biomass productivity $^{23,24}$ is critical to the development of sustainable biofuel crops ${ }^{1}$ that are with optimized resource capture, allocation, storage, and utilization. Starch granule formation and metabolism in ray cells are relevant to wood formation, stem growth, and productivity in that those processes impact cambial dormancy and reactivation, which are key to adaptation of plants to such seasonal variations. ${ }^{25-27}$

Given the apparent regularity of the side-chain amylopectin cluster size, ${ }^{2}$ the size and structure of starch granules vary greatly with plant group; additional research is needed to capture the nanoscale variability between and within individual species. Whether or not connections can be made between the starch structures of woody feedstock, the physical and physiological processes in biomass plant tissues and cells, and the challenges of ethanol production have yet to be explored. Populus, being a nonfood source and one of the fastest growing trees in the temperate latitudes, is a promising feedstock for biofuels. ${ }^{28}$ Whereas associations between Populus starch accumulation and the genotype are being observed when studying the response to abiotic factors, such as drought stressors, ${ }^{23,24}$ the role of starch structure is unknown and in need of investigation (see section S5 in the Supporting Information for more discussion).

\section{RESULTS AND DISCUSSIONS}

Dimensional Quantification of in Situ Starch Granules. Electron microscopy of the prepared plant materials proves a useful initial approach to nanometrology, as shown in Figure 1. Studying the images acquired for a stem xylem

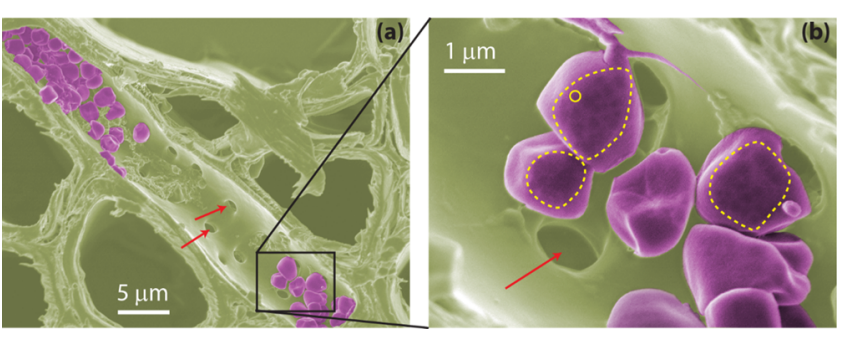

Figure 1. SEM of starch granules (purple) in untreated Populus within xylem region of the stem sample. Color was artificially assigned to better visualize the structures. (a) Accumulation in ray RP cells with simple (unbordered) pits (red arrows). (b) Substructures of $\sim 100-$ $250 \mathrm{~nm}$ (inside the dashed yellow lines regions) are revealed within the granules as dark speckles, possibly surface pores, or blocklets. A yellow circle of $150 \mathrm{~nm}$ diameter marks one of the dark regions.

structure, we observed certain morphological features agglomerated on or near specific surface regions of the investigated cross sections. Upon closer inspection, the features may be identified to be starch granules, ${ }^{29}$ which are observed to be mainly localized within the ray parenchyma (RP) cells of the stem sample. One of the functions of the RP includes the storage and transport of nonstructural carbohydrates (NSCs).

Depending on the location of the cross-sectional cut of the sample, the contents of RP cells may be only partially exposed (see Figures S1 and S2 in the Supporting Information). The external morphology of the starch granules takes polygonal shapes of irregular size, shape, and number of facets. Analyzing the SEM images of granules from several RP cells, we have evaluated their dimensions by measuring the perimeter of their projected top facet, assuming an elliptic shape. With an average top facet circularity of 0.70 and perimeter of $4.7 \pm 0.9 \mu \mathrm{m}$, the average diameter is determined to be $1.5 \pm 0.3 \mu \mathrm{m}$ and the volume $1.75 \pm 0.03 \mu \mathrm{m}^{3}$ (see Figure S3 in Supporting Information). The diameter can range from less than 1 to 300 $\mu \mathrm{m}$ depending on the plant source, making Populus starch granules one of the smallest. In contrast to the observed fairly uniform granule size, other granules (e.g., Norway spruce needles, Wheat) have a wide ranging size, from 0.5 to $10 \mu \mathrm{m}$ in diameter. ${ }^{13,14,30}$

Round substructures can be observed through the partially transparent outer surface (yellow dashed region in Figure 1b), with diameters of $100-250 \mathrm{~nm}$. The surface of the granule appears to be smooth with the dark speckles residing under a thin layer. The distribution and size variation are suggestive of evidence of surface pores ${ }^{31}$ or of blocklets. ${ }^{8}$ Furthermore, the 

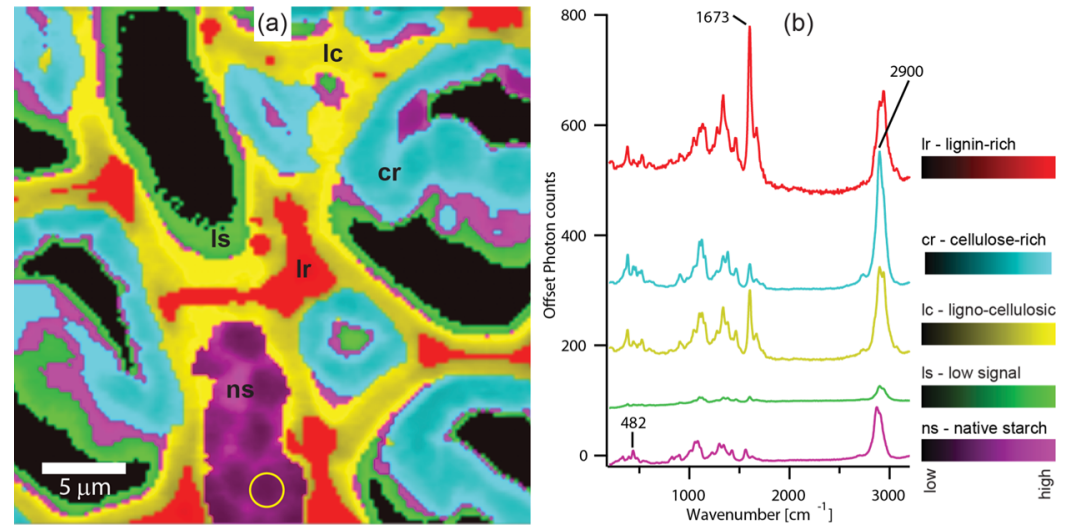

Figure 2. Confocal Raman microscopy of untreated raw Populus. (a) Chemical identification of native starch (purple) is distinct from cr (lightblue), lc (yellow), and lignin-rich (red) areas. A yellow circle of $2 \mu \mathrm{m}$ diameter is positioned over a granule. (b) Average Raman signal for each cluster partition, offset in the $y$-axis for clarity. The $1 \mathrm{r}$ partition is distinguished by the $1670 \mathrm{~cm}^{-1}$ line, and the cr partition by the $2900 \mathrm{~cm}^{-1}$ line. The lc partitions contain both lines, whereas $\mathrm{ns}$ is distinguished by the line at $482 \mathrm{~cm}^{-1}$.

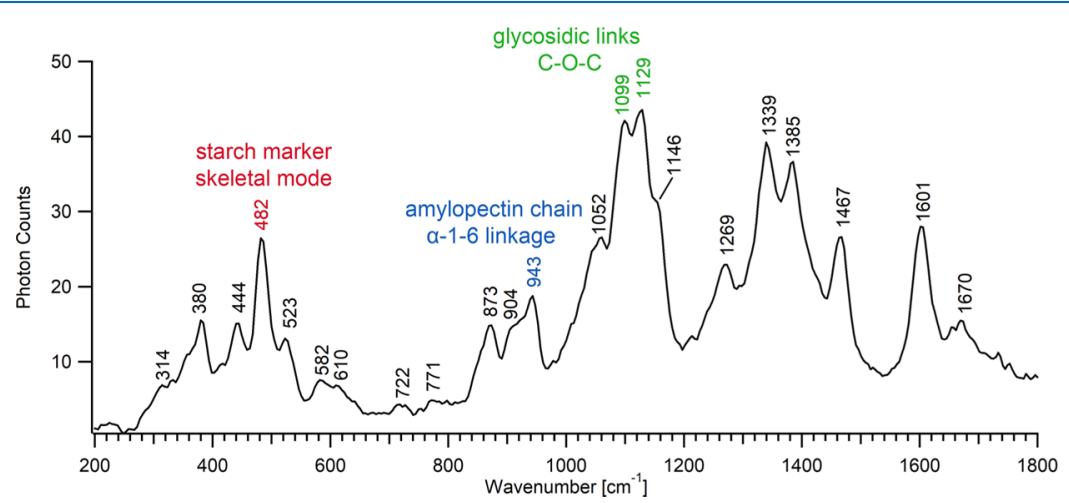

Figure 3. Raman spectra of in situ native Populus carbohydrate granules.

observed holes in the ray cell walls are identified to be pits, with nearly round diameters of around $1 \mu \mathrm{m}$. Whereas bordered pits are found in numerous species of woody dicotyledons, the pits in our sample appear to be simple and nonbordered.

Chemical Signature of in Situ Starch Granules. Multimodal and correlative imaging and analysis of subcellular features and complex systems, such as starch granules in woody xylem, are highly needed measurement capabilities. Specifically, further studies by overlaying the observed SEM-derived morphological features in Figure 1 with chemical information, such as obtained from Raman spectroscopy, ${ }^{32}$ may prove useful. For example, principal component analysis of the Raman spectra is a promising technique for quantifying amylose content. ${ }^{33,34}$ Similarly, employing confocal Raman microscopy, the characteristic spectral features of major polymers of lignin, cellulose, and hemicellulose have been shown to be sufficient in recognizing specific domains and compositions $^{34}$ of plant cell walls. Therefore, here, we carry out Raman spectroscopy of a $20 \mu \mathrm{m}$ thick cross section of untreated raw stem to generate the needed spectral images. As shown in Figure 2a, the processed Raman map reveals $\sim 2 \mu \mathrm{m}$ diameter granules (purple) in the RP with distinct red ligninrich (lr), light blue cellulose-rich (cr), and yellow lignocellulosic (lc) regions characteristic of cross-sectional wood cells. A green region of low-signal (ls) is due to the receding sample surface becoming out of focus with the instrument.

The corresponding average spectra for each cluster (Figure 2b) show lignin-rich regions with the characteristic $1467 \mathrm{~cm}^{-1}$
( $\mathrm{C}=\mathrm{C}$ stretching), whereas $\mathrm{cr}$ regions are indicated by the peak at $2900 \mathrm{~cm}^{-1}$ (C-H stretching). The lc (yellow) regions contain both characteristic peaks at 1673 and $2900 \mathrm{~cm}^{-1}$, however not as strong. The Raman peaks of the purple nativestarch (ns) cluster indicate that the composition is neither lignin nor cellulose, having no major peak at $1467 \mathrm{~cm}^{-1}$ or at $2900 \mathrm{~cm}^{-1}$. The new band $482 \mathrm{~cm}^{-1}$, seen in the skeletal-mode region, is an indicator of starch. The $\mathrm{C}-\mathrm{H}$ stretching region, $3100-2900 \mathrm{~cm}^{-1}$, is not expected to be dramatically different between starch and the constituents of the cell wall. The spectra are also compared to those of storage polysaccharides (starch or polymeric carbohydrate molecules) extracted from potato and ergosterol (sterol from cell membranes of fungi and protozoa). The strong peaks of the purple cluster at 2913 and $482 \mathrm{~cm}^{-1}$ fairly matched the potato starch at 2933 and 482 $\mathrm{cm}^{-1}$ (see Figure S4 in the Supporting Information). The lines relevant to carbohydrate are well-known. ${ }^{32,33,35}$ A further analysis of the native starch spectra is shown in starch spectra shown in Figure 3 with major band assignments listed in Table 1. The $\alpha-1-6$ linkage of the amylopectin chain is identified at $943 \mathrm{~cm}^{-1}$. We also found peaks at 1467, 1385, 1339, 1269 $\mathrm{cm}^{-1}$, glycosidic links $\left(1129\right.$ and $\left.1099 \mathrm{~cm}^{-1}\right)$, and $873 \mathrm{~cm}^{-1}$ with shoulders at 1146, 1052, and $904 \mathrm{~cm}^{-1}$. Additionally, ring modes $\left(722,772 \mathrm{~cm}^{-1}\right)$ and the skeletal modes (380, 444, 482, 523 , and $582 \mathrm{~cm}^{-1}$ with shoulders at 314 and $\left.610 \mathrm{~cm}^{-1}\right)$ were present. For our species of Populus, the observed starch marker peak at $482 \mathrm{~cm}^{-1}$ falls within the $475-485 \mathrm{~cm}^{-1}$ marker range for starch. 
Table 1. Assignment of Lines in Populus Raman Spectra Attributed to Carbohydrate 36,37

\begin{tabular}{ll} 
band position ${ }^{a}\left(\mathrm{~cm}^{-1}\right)$ & \multicolumn{1}{c}{ assignment } \\
$2913 \mathrm{vs}$ & $\mathrm{C}-\mathrm{H}$ stretching \\
$1467 \mathrm{vs}$ & $\mathrm{CH}$ deformation \\
$1385 \mathrm{vs}$ & $\mathrm{C}-\mathrm{H}$ bending \\
$1339 \mathrm{vs}$ & $\mathrm{C}-\mathrm{O}-\mathrm{H}$ bending \\
$1269 \mathrm{~s}$ & $\mathrm{CH}$ OH related mode \\
$1146 \mathrm{~m}(\mathrm{sh})$ & $\mathrm{C}-\mathrm{O}, \mathrm{C}-\mathrm{C}, \mathrm{C}-\mathrm{H}$ related modes \\
$1129 \mathrm{vs}$ & glycosidic link C-O-C \\
$1099 \mathrm{vs}$ & glycosidic link C-O-C \\
$1052 \mathrm{~s}(\mathrm{sh})$ & $\mathrm{C}-\mathrm{O}-\mathrm{H}$ bending \\
$943 \mathrm{~s}$ & $\mathrm{C}-\mathrm{O}-\mathrm{C} \alpha-1-6$ linkage \\
$904 \mathrm{~m}(\mathrm{sh})$ & $\mathrm{C}-\mathrm{O}-\mathrm{H}$ bending \\
$873 \mathrm{~m}$ & $\mathrm{C}-\mathrm{O}-\mathrm{C}$ ring breathing \\
$771 \mathrm{w}$ & ring modes \\
$722 \mathrm{w}$ & ring modes \\
$610 \mathrm{w}(\mathrm{sh})$ & skeletal modes \\
$582 \mathrm{w}$ & skeletal modes \\
$523 \mathrm{~m}$ & skeletal modes \\
$482 \mathrm{vs}$ & skeletal modes (marker) \\
$444 \mathrm{~m}$ & skeletal modes \\
$380 \mathrm{~m}$ & skeletal modes \\
$314 \mathrm{~m}(\mathrm{sh})$ & skeletal modes \\
$54 \mathrm{on}$ &
\end{tabular}

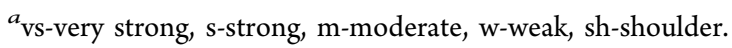

Physical Properties of in Situ Starch Granules. Having identified the chemical composition of the observed granular features, we then examine their individual morphological and mechanical properties using AFM in imaging and force measurement modes. As force mapping is highly dependent on the AFM tip environment (contact surface), granules are chosen with a flat top facet. To locate and select the granules, we first acquired large-scale topographic images (Figure 4a). We then employed sMNA to carve out a segment of the surface and mechanically expose the interior of the granule (see Experimental section). In contrast to other cited methods, the sMNA does not alter the integrity of the sample. Quantitative analyses were obtained on three different granules from the same untreated Populus cross section.

Nanoablation for Morphological Investigation. Ablating $\sim 300 \mathrm{~nm}$ of the top surface (Figure 4c) was sufficient to remove the outer layer and to expose the inner structure of a single granule. The higher-resolution topographic measurements confirmed the presence of highly ordered substructures (Figure 4d). By analyzing the cross-sectional profiles (red dotted curves in Figure 4b), taken at the dotted lines in Figure $4 \mathrm{~d}$, a highly ordered, close-packed structure is revealed and interpreted to be blocklets. The surface roughness extracted from topographic images was found to be $\sim 3 \mathrm{~nm}$ before ablation, shown as the blue curve in Figure $4 \mathrm{~b}$. After ablation, the height of the cross-sectional surface profiles at the red dotted curves were measured to be $\sim 30 \mathrm{~nm}$, neglecting the two large bumps considered to be debris from the ablation. The high periodicity in both profiles confirms blocklet substructure with dimensions of $160 \pm 30$ and $200 \pm 30 \mathrm{~nm}$, respectively (Figure 4b), in agreement with the reported range. ${ }^{8}$ We survey the closed-packed arrangement by outlining the edges of the topography, indicating a diamond-shaped packing of blocklets, as seen from the top surface side of the inner layer (Figure 4e). In observing the orthogonal orientation or cross section of the growth layer in the phase image in Figure $4 f$, the patterns in the region demarcated with a black dashed line suggest a thickness of a single blocklet to be $\sim 150 \mathrm{~nm}$, indicated by the green bar. Using a diameter of an amylopectin side-chain cluster of 9-10 nm and an average blocklet length of $150 \mathrm{~nm}$, the blocklets are estimated to contain 15-17 lamellae. Note that ring growths ${ }^{8,17}$ composed of alternating amorphous and semicrystalline layers were not observed. The growth ring model is mainly used to describe large starch granules (above $10 \mu \mathrm{m}$ ) and does not apply to the $1 \mu \mathrm{m}$-size Populus starch granules. Instead, our result suggests a core-shell structure made of one $\sim 300 \mathrm{~nm}$-size amorphous outer layer and one $\sim 150 \mathrm{~nm}$-size blocklet layer (see section S4 in the Supporting Information).

An advantage of using the sMNA for the study of starch architecture is the capability of obtaining highly controlled multiple views of the starch structure. As a demonstration, two ablated areas (blue and red) from two different granules are imaged showing the blocklet substructure (Figure $4 \mathrm{~g}$ ). Even at a low resolution, the numerical $\left(150 \times 100\right.$ pixel $\left.^{2}\right)$ zoom of the blue region (Figure $4 \mathrm{~h}$ ) indicates an organized substructure. ${ }^{38}$ The spatial frequency of the topographical features is quantified from the $\left(512 \times 256\right.$ pixel $\left.^{2}\right)$ zoomed $(1 \times 0.5$ $\mu \mathrm{m}^{2}$ ) image (Figure $4 \mathrm{i}$ ) of the red region in Figure $4 \mathrm{~g}$. From the associated Fourier power spectral density, the periodicity of the observed nanostructures is determined to be $156 \mathrm{~nm}$, in agreement with the profile measurement.

Nanoablation for Nanomechanical Investigation of in Situ Starch Granules. Nanomechanical properties, expressed in terms of Young's modulus $(E)$ and viscoplasticity index $(\mathrm{PI})^{34}$ of the starch granules, may shed further light onto the granule structure; however, few studies have been conducted mainly because of the lack of accessibility to the inner structure. Such information can be extracted from nanoindentation by a sharp AFM tip ${ }^{34}$ into the granule and its substructures. Force mapping was thus performed on both the outer surface and the inner ablated surface exposing the substructure. Figure 5 displays both the topographic and the mechanical properties extracted before (Figure $5 \mathrm{a}, \mathrm{b}, \mathrm{e}, \mathrm{f}, \mathrm{i}, \mathrm{j}, \mathrm{m}, \mathrm{n}$ ) and after (Figure 5c,d,g,h,k,l,o,p) granule ablation. Topographical imaging of the outer surface (Figure 5a) is zoomed in to show nanometer-scale roughness (Figure $5 \mathrm{~b}$ ), with additional detail in the corresponding phase images (Figure $5 e, f)$. The topography of the inner surface (Figure $5 c, d$ ) is supported with corresponding phase images that have strong features of the exposed substructures (Figure 5g,h). E mappings of the surfaces (Figure $5 \mathrm{i}, \mathrm{k}$ ) located by the marked yellow regions (Figure 5a,c) were extracted from forcedeformation curves measured during the tip-sample interaction during indention (see Experimental section). Young's modulus distributions, extracted from $E$ mapping, illustrated as histograms in Figure 5j,l, were computed to determine the average $E$ values for each case. The outer surface has a predominantly homogeneous $E$ with an average value of $10.8 \pm$ $2.4 \mathrm{GPa}$ (Figure 5i). The inner exposed region, appearing in brown (Figure 5k), shows a large increase of $E$ of $31.7 \pm 9.9$ $\mathrm{GPa}$, reflecting the nanolayer-dependent mechanical property differences of the granule. The difference in $E$ may be suggestive of differences in the physical properties (e.g., density) of the amorphous top and semicrystalline inner layers. ${ }^{1}$

The exposed inner blocklet regions are expected to be semicrystalline, containing a higher ratio of amylopectin (a large macromolecule of $10^{7}$ to $10^{9} \mathrm{Da}$ molecular weight with a 

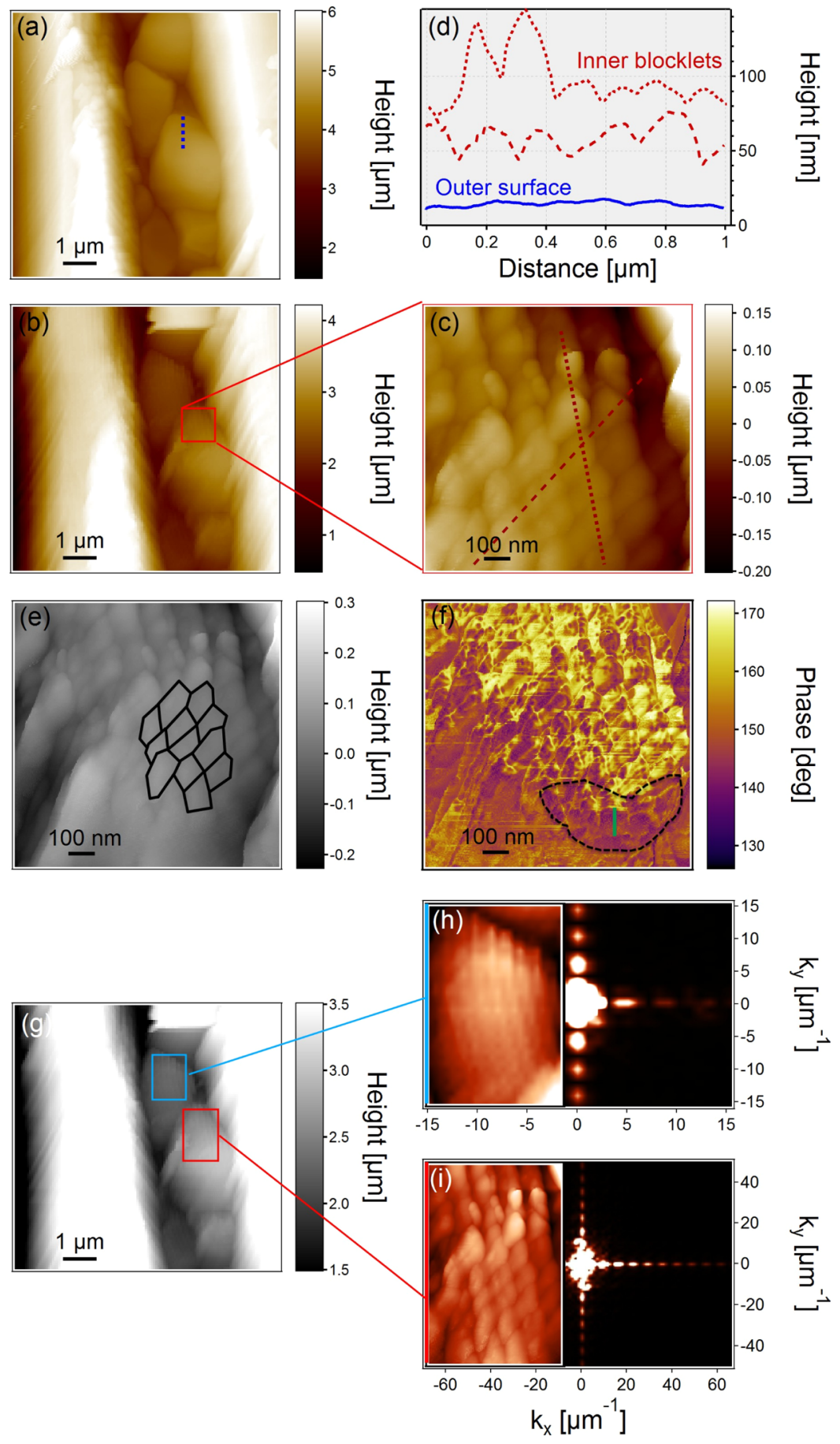

Figure 4. AFM imaging inside a radial RP cell containing several starch granules. (a) Topography of the outer shell before ablation. The blue dotted line is the location for profile analysis. (b) Profiles along the marked dotted lines (marked in a and d) showing the roughness difference at the surface $(\approx 3 \mathrm{~nm})$ and inside $(\approx 30 \mathrm{~nm})$ the starch granules. (c) Exposed inner structures after removing the outer layer of the granules. $(\mathrm{d}) 1 \times 1$ $\mu \mathrm{m}^{2}$ zoom, highlighting the presence of nanometric blocklets inside the granules. The two red dotted lines are the locations for profile analysis in (b). (e) Topographic image in gray scale to highlight that blocklets occur in different shapes (outlined edges in black). (f) A view of the side shown in the region marked by the black dotted line provides evidence of one blocklet of $\sim 150 \mathrm{~nm}$ thick, indicated by the green bar. (g) Marked areas containing periodicity (blue and red boxes) on the exposed surface of two different granules after ablation. (h,i) Fourier power spectral densities of the respective images (insets) showing the spatial dispersion of the substructure components. (h) Numerical low-resolution zoom $(150 \times 100$ pixel $\left.^{2}\right)$ of (g). (i) High-resolution zoom of $(\mathrm{g})\left(512 \times 256 \mathrm{pixel}^{2}\right)$.

density of $1.5 \mathrm{~g} / \mathrm{cm})$, whereas the outer shell may be amorphous, composed of more amylose (molecular weight $10^{5}$ to $\left.10^{6} \mathrm{Da}\right)$. In addition, the blue-green zones surrounding the exposed region in the $E$ image (Figure $5 \mathrm{k}$ ) can be associated with the outer surface and cell wall materials. This change in mechanical properties over the exposed area is also manifested in the phase imaging (Figure 5h), which is highly sensitive to viscoelasticity. ${ }^{39}$ Changes in adhesion energy, which could also contribute to the change in the phase was shown to be negligible (see Figure S5 in the Supporting 

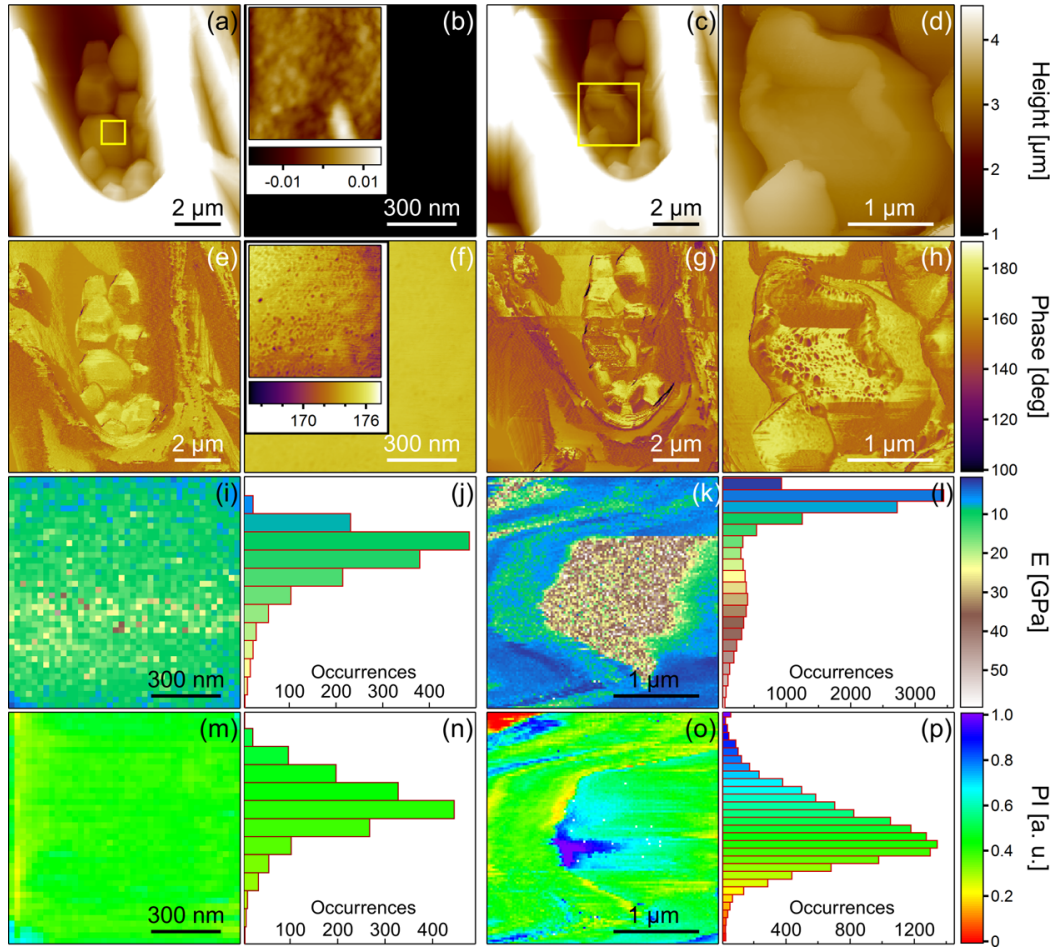

Figure 5. Mechanical properties of starch granules through nanomechanical force measurements on a single granule. A comparison between the unablated outer surface $(\mathrm{a}, \mathrm{b}, \mathrm{e}, \mathrm{f}, \mathrm{i}, \mathrm{j}, \mathrm{m}, \mathrm{n})$ and the region of the inner surface after ablation $(\mathrm{c}, \mathrm{d}, \mathrm{g}, \mathrm{h}, \mathrm{k}, \mathrm{l}, \mathrm{o}, \mathrm{p})$ reveals differences in topography, $E$ and, PI. In $(a, c)$, the yellow squares on the topographical images mark the zoomed regions in the outer surface $(b, f, i, j, m, n)$ and inner surface $(d, h, k, l, o, p)$, respectively. The phase images $(e-h)$ provide additional detail to the topographical images $(a-d)$, where greater roughness is observed in the inner surface (h). The E mapping and the resulting distribution histogram of the inner surface, $(\mathrm{k}, \mathrm{l})$, respectively, is a factor of 3 larger than the outer surface, ( $\mathrm{i}, \mathrm{j})$, respectively. The PI mapping and resulting distribution histogram of the inner surface (o,p), respectively, is a factor of 2 larger than the outer surface $(m, n)$, respectively.

Information). PI is an informative mechanical property that reflects the ratio of elastic and viscoplastic deformations sustained by the granule surface during the indentation measurements (Figure $5 \mathrm{~m}-\mathrm{p}$ ). When PI equals 1 , the material behavior is fully viscoplastic, whereas for a PI equals 0 , it is fully elastic. Figure 5o shows an increase of PI from 0.4 to 0.8 after granule ablation, implying an increase of the viscoplasticity. Previous work using contact AFM abrasion on unmodified wheat starch granules showed an increase in the hardness by a factor of 4 before and after abrasion of the surrounding gluten (protein) layer. ${ }^{13,14}$ However, in this work, the blocklet structure was not distinguished, thus a direct comparison cannot be made.

\section{CONCLUSIONS}

From the analysis of the in situ images, the observed granular features, resolved by electron microscopy, were measured to be $1.5 \pm 0.3 \mu \mathrm{m}$ in size. The results from confocal Raman microscopy showed that the observed features emit strong Raman radiation at $943 \mathrm{~cm}^{-1}$ because of the amylopectin chain of the starch. From further morphological investigation using AFM, we confirmed that the features, predominantly found in the ray $\mathrm{RP}$ cells, were starch granules of young untreated woody xylem. It can therefore be concluded that the molecular composition of the granules includes amylose and amylopectin. The application of sMNA to the granule outer layer was effective in precisely controlling mechanical exposure of the inner layer without chemically treating or altering the sample, thus allowing subsequent topographic analysis to reveal highly ordered blocklets of $\sim 160 \mathrm{~nm}$ size. This new experimental evidence confirms that Populus starch granules possess nanometer-sized blocklets, a potential biofuel feedstock. The previously reported formation layers or growth rings, found inside large granules, ${ }^{8,9,15}$ were not observed in our samples, mainly because of their small size (around $1.5 \mu \mathrm{m}$ in diameter), but a core-shell model structure is suggested. In addition, the self-assembling of the blocklets was confirmed via Fourier image processing, resulting in a periodicity of $156 \mathrm{~nm}$ and indicating that the ordered inner structure is semicrystalline.

The sMNA facilitated the observation of the remarkable topographical detail of the semicrystalline blocklet structure, not seen previously via other techniques. Furthermore, the quantitative mechanical measurements provided information on the Young's modulus and viscoplastic index heterogeneity of the material at a nanoscale level, distinguishing the inner and outer granule regions. We report a Young's modulus of $10.8 \pm$ $2.4 \mathrm{GPa}$ for the outer layer and three times larger for the blocklet substructures, that is, $E=31.7 \pm 9.9 \mathrm{GPa}$. These differences could be due to the different distributions of amylose and amylopectin, which have different densities. Importantly, we found a much higher viscoplastic behavior for the internal layer, providing new information on the starch granule structure. The demonstrated ablation technique was proposed here as an integral part of a multimodal nanoscale approach to achieving soft alteration of core-shell materials with weak interlayer coupling without damaging the nanostructures inside the granule. The presented results demonstrate a powerful application of multimodal AFM for quantitative in situ determination of the properties of a specific plant substructure here, starch granule, opening up its potential 
to clarify more complex secondary cell wall features. Application of this technique in the future to study starch granules under biotic or abiotic stresses can aid in mechanistic understanding of the relevance of genetically determined factors and external signals in defining plant productivity and health. ${ }^{23-27,40}$

\section{EXPERIMENTAL SECTION}

Sample Preparation. The samples of fresh Populus were harvested from stems of greenhouse-grown plants rapidly growing Populus tremula $\times$ alba (clone 717 ) wild-type plants, noting that starch granules are produced within the $\mathrm{RP}^{40}$ in spring and summer in field-growing plants. ${ }^{27}$ Though there is a small effect because of temperature and light quality throughout the year, our greenhouse conditions remained within the ambient range. Thus, greenhouse-grown plants, unlike field-grown plants, do not necessarily synthesize, store, and mobile starch according to seasons. The samples did not undergo fixation, infiltration, staining, and processing steps but the sectioned samples were still minimally processed. Freshly harvested stem samples were embedded in Tissue-Tek O.C.T. Compound (Sakura Finetek), quickly flash-frozen, and sectioned immediately with a cryomicrotome (Leica Cryostat) using a disposable blade to obtain $15 \mu \mathrm{m}$ thick sections. To maintain structural integrity of the cell walls, all samples were stored and dried between glass slides. Initially, the freshly cut cross sections were washed with DI water and some were set aside as UR (untreated raw) samples.

Scanning Electron Microscopy. SEM measurements were performed using JEOL JSM-6340F equipment, at an acceleration voltage of $3 \mathrm{kV}$. To get a better contrast with the SEM, the samples were slightly coated with carbon using a 99.9\% pure graphite source. This process typically results in a few tens of nanometers $(\sim 20 \mathrm{~nm})$ sputtered on the sample. The AFM images were not acquired from the coated samples.

Extraction of Granule Dimensions. Granule dimensions were extracted from SEM images using ImageJ software. Because granules have polygonal shapes of irregular facet numbers and dimensions, and we have access to twodimensional projections only, volume dimensions cannot be determined accurately. Dimensions reported in the paper have been approximated by measuring the perimeter of the top facet of each granule and assuming an ellipsoid shape (see Figures S1-S3 in the Supporting Information).

Raman Confocal Microscopy. Confocal Raman images of the samples were acquired with a WITec Alpha500R near field scanning optical microscope at an excitation wavelength of 532 $\mathrm{nm}$. Raman spectra was taken at a resolution of $4 \mathrm{~cm}^{-1}$. A $100 \times$ objective provided $\sim 320 \mathrm{~nm}$ spatial resolution. Images were obtained by raster scanning at a $200 \mathrm{~nm}$ step size and 0.5 $\mathrm{s}$ integration time. $\mathrm{K}$-means cluster analysis was used to create Raman cluster images.

Atomic Force Microscopy. AFM and spectroscopy were used to extract topographic information and mechanical properties at the nanoscale for starch granules. All measurements were obtained using the NTEGRA AFM system from NT-MDT and AFM tips from Mikromash (NSC15, resonance frequency $f \approx 150 \mathrm{kHz}$, apex radius $r=8 \mathrm{~nm}$, spring constant in the range $30-35 \mathrm{~N} / \mathrm{m}$ ). Note that prior to and after each measurement, the spring constant was calibrated using the thermal noise method and measuring the cantilever sensitivity by pressing the tip over a hard glass substrate. Mapping of the Young's modulus was extracted from the beginning of unloading curves of discrete force curve measurements realized at each point of a $120 \times 120$ array by using the Sneddon contact mechanics, assuming a conical tip in contact with a flat surface. ${ }^{41}$ In all cases, the adhesion was found to be generally smaller than $10 \%$ of the applied loading force and was considered negligible in the model. Curves were obtained at a frequency of $1 \mathrm{~Hz}$. Poisson ratio was 0.4 for the sample. ${ }^{42}$ The viscoplasticity index was obtained following the method reported in ${ }^{43,44}$ by considering the ratio of the areas below the loading and unloading curves of the force measurements. A plasticity index of PI $=1$ yields a fully plastic material, whereas $\mathrm{PI}=0$ corresponds to a perfectly elastic response. For $E$ and PI mappings of (Figure 5i), an array of $40 \times 40$ discrete curves, covering a $1 \times 1 \mu \mathrm{m}^{2}$ region, was performed, whereas a $120 \times$ 120 array was used in (Figure $5 \mathrm{k}$ ), covering a $3 \times 3 \mu \mathrm{m}^{2}$ region.

Nanoablation Using AFM. We have developed a mechanical nanoablation technique, named in analogy with laser ablation, in order to separate the different layers of the core-shell starch granule. Similar to indentation mapping, the AFM tip is used as a nanocutter. The ablation is carried out by scanning the sample with the probe with a force sufficiently high to cut the nonconnected shell layer of the granule. In our experiment, a force of about $1.5 \mu \mathrm{N}$ was required to uncouple both layers. We note from Figure 5 that only the shell layer is affected by the ablation, where the surrounding cell walls are unmodified.

\section{ASSOCIATED CONTENT}

\section{Supporting Information}

The Supporting Information is available free of charge at https://pubs.acs.org/doi/10.1021/acsomega.9b02849.

Dimensional quantification; chemical confirmation through Raman spectroscopy; adhesion energy mappings; core-shell representation of a single Populus starch granule; and applications to biomass delignification (PDF)

\section{AUTHOR INFORMATION}

\section{Corresponding Author}

Ali Passian - Computational Sciences and Engineering Division and BioEnergy Science Center, Biosciences Division, Oak Ridge National Laboratory, Oak Ridge, Tennessee 37830, United States; Department of Chemical and Biomolecular Engineering and Department of Physics, University of Tennessee, Knoxville, Tennessee 37996, United States; ○ orcid.org/0000-00024736-4157; Email: passianan@ornl.gov

\section{Authors}

Rubye H. Farahi - Computational Sciences and Engineering Division, Oak Ridge National Laboratory, Oak Ridge, Tennessee 37830, United States

Aude L. Lereu - Aix Marseille University, CNRS, Centrale Marseille, Institut Fresnel, Marseille 13397, France; (1) orcid.org/0000-0001-7390-7832

Anne M. Charrier - Aix Marseille University, CNRS, CINaM, Marseille 13288, France; 이이. orcid.org/0000-0002-0205-1341

Udaya C. Kalluri - BioEnergy Science Center, Biosciences Division, Oak Ridge National Laboratory, Oak Ridge, Tennessee 37830, United States

Brian H. Davison - BioEnergy Science Center, Biosciences Division, Oak Ridge National Laboratory, Oak Ridge, 
Tennessee 37830, United States; Department of Chemical and Biomolecular Engineering, University of Tennessee, Knoxville, Tennessee 37996, United States

Complete contact information is available at:

https://pubs.acs.org/10.1021/acsomega.9b02849

\section{Author Contributions}

R.H.F. and A.L.L. have made equal contributions to this work. R.H.F., A.L.L., A.M.C., and A.P. carried out the experiments. R.H.F., A.L.L., A.M.C., and A.P. wrote the paper with feedback from all the authors. All the authors reviewed the paper.

\section{Notes}

The authors declare no competing financial interest.

\section{ACKNOWLEDGMENTS}

We would like to thank Damien Chaudanson at CINaM for the raw SEM images. This work was sponsored by the BioEnergy Science Center (BESC) of the Oak Ridge National Laboratory (ORNL). The BESC is a US Department of Energy (DOE) Bioenergy Research Center supported by the Office of Biological and Environmental Research (BER) in the DOE Office of Science. ORNL is managed by UT-Battelle, LLC, for the US DOE under contract DE-AC05-00OR22725. This work was also sponsored by the A*MIDEX foundation on the Innovation and Emergence AAP2017 (project no: A-MAAP-EI-17-10-170224-18.04-CHARRIER-E) and the CNRS through the PICS2019 program.

\section{REFERENCES}

(1) Pfister, B.; Zeeman, S. C. Formation of starch in plant cells. Cell. Mol. Life Sci. 2016, 73, 2781-2807.

(2) Jenkins, P. J.; Cameron, R. E.; Donald, A. M. A universal feature in the structure of starch granules from different botanical sources. Starch-Starke 1993, 45, 417-420.

(3) Tang, H.; Mitsunaga, T.; Kawamura, Y. Molecular arrangement in blocklets and starch granule architecture. Carbohydr. Polym. 2006, 63, 555-560.

(4) Pérez, S.; Bertoft, E. The molecular structures of starch components and their contribution to the architecture of starch granules: A comprehensive review. Starch-Starke 2010, 62, 389-420.

(5) Hizukuri, S. Relationship between the distribution of the chainlength of amylopectin and the crystalline-structure of starch granules. Carbohydr. Res. 1985, 141, 295-306.

(6) Cheetham, N. W. H.; Tao, L. Variation in crystalline type with amylose content in maize starch granules: an X-ray powder diffraction study. Carbohydr. Polym. 1998, 36, 277-284.

(7) Putaux, J.-L.; Molina-Boisseau, S.; Momaur, T.; Dufresne, A. Platelet nanocrystals resulting from the disruption of waxy maize starch granules by acid hydrolysis. Biomacromolecules 2003, 4, 11981202.

(8) Gallant, D. J.; Bouchet, B.; Baldwin, P. M. Microscopy of starch: Evidence of a new level of granule organization. Carbohydr. Polym. 1997, 32, 177-191.

(9) Huang, J.; Wei, N.; Li, H.; Liu, S.; Yang, D. Outer shell, inner blocklets, and granule architecture of potato starch. Carbohydr. Polym. 2014, 103, 355-358.

(10) Baker, A. A.; Miles, M. J.; Helbert, W. Internal structure of the starch granule revealed by AFM. Carbohydr. Res. 2001, 330, 249-256.

(11) Baldwin, P. M.; Davies, M.; Melia, C. D. Starch granule surface imaging using low-voltage scanning electron microscopy and atomic force microscopy. Int. J. Biol. Macromol. 1997, 21, 103-107.

(12) Baldwin, P. M.; Adler, J.; Davies, M. C.; Melia, C. D. High resolution imaging of starch granule surfaces by atomic force microscopy. J. Cereal Sci. 1998, 27, 255-265.
(13) Chichti, E.; George, M.; Delenne, J.-Y.; Lullien-Pellerin, V. Changes in the starch-protein interface depending on common wheat grain hardness revealed using atomic force microscopy. Plant Sci. 2015, 239, 1-8.

(14) Chichti, E.; George, M.; Delenne, J.-Y.; Radjai, F.; LullienPellerin, V. Nano-mechanical properties of starch and gluten biopolymers from atomic force microscopy. Eur. Polym. J. 2013, 49, 3788-3795.

(15) Buléon, A.; Colonna, P.; Planchot, V.; Ball, S. Starch granules: structure and biosynthesis. Int. J. Biol. Macromol. 1998, 23, 85-112.

(16) Manners, D. J. Recent developments in our understanding of amylopectin structure. Carbohydr. Polym. 1989, 11, 87-112.

(17) Wang, S.; Copeland, L. Effect of Acid Hydrolysis on Starch Structure and Functionality: A Review. Crit. Rev. Food Sci. Nutr. 2015, $55,1081-1097$.

(18) Oostergetel, G. T.; van Bruggen, E. F. J. The crystalline domains in potato starch granules are arranged in a helical fashion. Carbohydr. Polym. 1993, 21, 7-12.

(19) Alcázar-Alay, S. C.; Meireles, M. A. A. Physicochemical properties, modifications and applications of starches from different botanical sources. Food Sci. Technol. 2015, 35, 215-236.

(20) MacNeill, G. J.; Mehrpouyan, S.; Minow, M. A. A.; Patterson, J. A.; Tetlow, I. J.; Emes, M. J. Starch as a source, starch as a sink: the bifunctional role of starch in carbon allocation. J. Exp. Bot. 2017, 68, $4433-4453$.

(21) Copeland, L.; Blazek, J.; Salman, H.; Tang, M. C. Form and functionality of starch. Food Hydrocolloids 2009, 23, 1527-1534.

(22) Le Corre, D.; Bras, J.; Dufresne, A. Starch Nanoparticles: A Review. Biomacromolecules 2010, 11, 1139-1153.

(23) Cao, X.; Jia, J.; Zhang, C.; Li, H.; Liu, T.; Jiang, X.; Polle, A.; Peng, C.; Luo, Z.-B. Anatomical, physiological and transcriptional responses of two contrasting poplar genotypes to drought and rewatering. Physiol. Plant. 2014, 151, 480-494.

(24) Regier, N.; Streb, S.; Cocozza, C.; Schaub, M.; Cherubini, P.; Zeeman, S. C.; Frey, B. Drought tolerance of two black poplar (Populus nigra L.) clones: contribution of carbohydrates and oxidative stress defence. Plant, Cell Environ. 2009, 32, 1724-1736.

(25) Begum, S.; Nakaba, S.; Oribe, Y.; Kubo, T.; Funada, R. Changes in the localization and levels of starch and lipids in cambium and phloem during cambial reactivation by artificial heating of main stems of Cryptomeria japonica trees. Ann. Bot. 2010, 106, 885-895.

(26) Bonicel, A.; Haddad, G.; Gagnaire, J. Seasonal-variations of starch and major soluble sugars in the different organs of young poplars. Plant Physiol. Biochem. 1987, 25, 451-459.

(27) Schrader, S.; Sauter, J. J. Seasonal changes of sucrose-phosphate synthase and sucrose synthase activities in poplar wood (Populus $\mathrm{x}$ canadensis Moench < robusta $>$ ) and their possible role in carbohydrate metabolism. J. Plant Physiol. 2002, 159, 833-843.

(28) Sannigrahi, P.; Ragauskas, A. J.; Tuskan, G. A. Poplar as a feedstock for biofuels: A review of compositional characteristics. Biofuels, Bioprod. Biorefin. 2010, 4, 209-226.

(29) Sauter, J. J.; Kloth, S. Plasmodesmatal frequency and radial translocation rates in ray cells of poplar (populus $\mathrm{x}$ canadensis moench robusta). Planta 1986, 168, 377-380.

(30) Cabalkova, J.; Pribyl, J.; Skladal, P.; Kulich, P.; Chmelik, J. Size, shape and surface morphology of starch granules from Norway spruce needles revealed by transmission electron microscopy and atomic force microscopy: effects of elevated $\mathrm{CO} 2$ concentration. Tree Physiol. 2008, 28, 1593-1599.

(31) Fannon, J. E.; Hauber, R. J.; Bemiller, J. N. Surface pores of starch granules. Cereal Chem. 1992, 69, 284-288.

(32) Wiercigroch, E.; Szafraniec, E.; Czamara, K.; Pacia, M. Z.; Majzner, K.; Kochan, K.; Kaczor, A.; Baranska, M.; Malek, K. Raman and infrared spectroscopy of carbohydrates: A review. Spectrochim. Acta, Part A 2017, 185, 317-335.

(33) Almeida, M. R.; Alves, R. S.; Nascimbem, L. B. L. R.; Stephani, R.; Poppi, R. J.; de Oliveira, L. F. C. Determination of amylose content in starch using Raman spectroscopy and multivariate calibration analysis. Anal. Bioanal. Chem. 2010, 397, 2693-2701. 
(34) Farahi, R. H.; Charrier, A. M.; Tolbert, A.; Lereu, A. L.; Ragauskas, A.; Davison, B. H.; Passian, A. Plasticity, elasticity, and adhesion energy of plant cell walls: nanometrology of lignin loss using atomic force microscopy. Sci. Rep. 2017, 7, 152.

(35) Kizil, R.; Irudayaraj, J.; Seetharaman, K. Characterization of irradiated starches by using FT-Raman and FTIR spectroscopy. J. Agric. Food Chem. 2002, 50, 3912-3918.

(36) Cael, S. J.; Koenig, J. L.; Blackwel, J. Infrared and Raman spectroscopy of carbohydrates .3. Raman-spectra of polymorphic forms of amylose. Carbohydr. Res. 1973, 29, 123-134.

(37) Wellner, N.; Georget, D. M. R.; Parker, M. L.; Morris, V. J. In situ Raman microscopy of starch granule structures in wild type and ae mutant maize kernels. Starch-Starke 2011, 63, 128-138.

(38) Elson, J. M.; Bennett, J. M. Calculation of the power spectral density from surface profile data. Appl. Opt. 1995, 34, 201-208.

(39) Scott, W.; Bhushan, B. Use of phase imaging in atomic force microscopy for measurement of viscoelastic contrast in polymer nanocomposites and molecularly thick lubricant films. Ultramicroscopy 2003, 97, 151-169.

(40) Sauter, J. J. Investigations on physiology of woody rays of poplar .i. seasonal changes in starch content in ray parenchyma. $Z$. Pflanzenphysiol. 1966, 55, 246.

(41) Sneddon, I. N. The relation between load and penetration in the axisymmetric boussinesq problem for a punch of arbitrary profile. Int. J. Eng. Sci. 1965, 3, 47-57.

(42) Green, D. W.; Winandy, J. E.; Kretschmann, D. E. Wood Handbook-Wood as an Engineering Material, Chapter 05: Mechanical Properties of Wood; U.S. Department of Agriculture, F. S., Forest Products Laboratory, University of Wisconsin: Madison, WI, 2010.

(43) Boschung, E.; Heuberger, M.; Dietler, G. Energy dissipation during nanoscale indentation of polymers with an atomic force microscope. Appl. Phys. Lett. 1994, 64, 1794-1796.

(44) Charrier, A. M.; Lereu, A. L.; Farahi, R. H.; Davison, B. H.; Passian, A. Nanometrology of Biomass for Bioenergy: The Role of Atomic Force Microscopy and Spectroscopy in Plant Cell Characterization. Front. Energy Res. 2018, 6, 11. 